\title{
Potential Benefits of Acupuncture for Enhanced Recovery in Gynaecological Surgery
}

\author{
Jeong-Eun $\mathrm{Yoo}^{\mathrm{a}}$ Dal-Seok $\mathrm{Oh}^{\mathrm{b}}$ \\ ${ }^{a}$ National Clinical Research Centre for Korean Medicine (NCRC), Pusan National University Korean Medicine Hospital (PNUKH), \\ Yangsan, South Korea; \\ ${ }^{b}$ Division for Medical Research, Korea Institute of Oriental Medicine (KIOM), Daejeon, South Korea
}

\section{Keywords}

Acupuncture - Enhanced recovery after surgery .

Gynaecological surgery · Post-operative symptoms

\section{Summary}

We aimed to evaluate if acupuncture can improve clinical benefits and patient satisfaction after gynaecological surgery supported by enhanced recovery after surgery (ERAS) programmes. Therefore, we evaluated patient as well as clinical outcome in patient recovery after surgery. We searched MEDLINE, PubMed and EMBASE for articles dealing with post-operative acupuncture and extracted 9 suitable studies. We expected acupuncture to alleviate surgical stress, reduce emetic symptom and accelerate recovery from complications in pre-, intra-, and post-operative phases. Gastrointestinal motility and coldness achieved the full improvement rate of $50 \%$. With regard to post-operative nausea and vomiting, 3 studies showed more than $30 \%$ and 1 showed $16 \%$ improvement. Sore throat and urinary retention achieved a mild improvement rate of $16 \%$ and $12 \%$, respectively. In this study, we demonstrated that acupuncture can enhance recovery in gynaecological surgery without adverse effects and thus should be considered in ERAS.

\section{Schlüsselwörter}

Akupunktur . Gesteigerte Erholung nach Operation . Gynäkologische Operation · Postoperative Symptome

\section{Zusammenfassung}

Ziel der Übersichtsarbeit war es zu überprüfen, ob Akupunktur den klinischen Nutzen und die Patientenzufriedenheit nach gynäkologischen Operationen steigern kann. Hierzu haben wir Studien mit Programmen zur gesteigerten Erholung nach der Operation (ERAS) herangezogen und den klinischen Nutzen als auch die Patientenzufriedenheit ausgewertet. Dabei haben wir die Datenbanken MEDLINE, PubMed und EMBASE durchsucht und 9 Arbeiten zur Anwendung von Akupunktur in der postoperativen Phase identifiziert. Die Ergebniserwartung umfasste eine Linderung des operativen Stresses, Reduktion des Erbrechens sowie Beschleunigung der Erholung von Komplikationen während der prä- intraund postoperativen Phase. Die gastrointestinale Motilität und Kälteempfinden besserten sich um den maximalen Wert von $50 \%$. In Bezug auf die postoperative Übelkeit und Erbrechen zeigte sich in 3 Studien eine Besserung von über 30\%; eine Studie berichtete eine 16\%ige Verbesserung mit Akupunktur. Halsschmerzen und Harnretention verbesserten sich geringfügig mit 16 bzw. $12 \%$. Aus unserer Untersuchung kann daher geschlossen werden, dass Akupunktur Wirksamkeitspotenzial für eine verbesserte Erholung nach einer gynäkologischen Operation aufweist und gerade aufgrund der nebenwirkungsfreien Qualität in ERAS berücksichtigt werden sollte.

\section{KARGER \\ Fax +497614520714

\section{(c) 2015 S. Karger GmbH, Freiburg}

$1661-4119 / 15 / 0222-0111 \$ 39.50 / 0$
Dal-Seok Oh, OMD (oriental medical doctor), $\mathrm{PhD}$ 


\section{Introduction}

Although operations are commonly performed to treat disease, they often result in uncomfortable conditions that are related to surgical stress. To overcome this situation and provide better outcomes, physicians try to perform efficient management programmes. Among these programmes, enhanced recovery after surgery (ERAS), also referred to as the fast-track surgery programme, is a multidisciplinary approach to reduce hospital stays, provide early discharge with fewer complications, increase quality of life and fulfill subjective satisfaction. The team members, including surgeons, nurses, anaesthesiologists, pain specialists, and physical therapy staff, all play a role in the success of the programme [1] The programme also helps to standardise operation procedures and to evaluate their validity.

Yet, there are some weak points in ERAS, especially regarding gynaecological surgery. Physicians point out, that e.g. women exhibit higher anxiety levels in a different way before surgery. As a consequence, the doctors prescribe different preanaesthetic medication regimens in men and women. Accordingly, postoperative nausea and vomiting (PONV) occurs more frequently in women than in men. In gynaecological pelvic surgery, for example, care must be taken to preserve gastrointestinal (GI) and ureterovesical function, as a feeling of femininity loss might occur in women undergoing hysterectomy. To reduce these adverse effects after surgery, acupuncture might provide an effective approach.

Acupuncture involves the stimulation of specific acupuncture points (acupoints) on the skin of the body by needle insertion, acupressure, moxibustion and cupping. Stimulating specific acupoints can harmonise imbalances in the flow of qi through channels known as meridians. The effects of acupuncture on pain control, anxiety disorders [2] and PONV are well known [3].

Therefore we aimed at evaluating acupuncture as a potentially useful element in ERAS to alleviate adverse effects after gynaecological surgery. For implementation in practice, we evaluated whether acupuncture could improve the clinical outcomes regarding clinical benefits and patient-reported outcome (PRO).

\section{Methods}

Search and Appraisal

MEDLINE, PubMed and EMBASE were searched for controlled studies on acupuncture in gynaecological surgery that had been published up to March 2014. The following keywords were used as queries: acupuncture OR moxibustion OR cupping AND gynaecological surgery OR hysterectomy OR laparoscopy. The searches were limited to human clinical trials, written in English. Duplicated articles from different databases were eliminated, and the title and abstract were screened. Those articles not relevant, e.g., on cholecystectomy, were excluded. Among the identified articles, only articles on gynaecological surgery for non-malignant conditions were included. Finally, data from 9 articles were analysed (fig. 1).

\section{ERAS Programme Organisation}

We extracted the core elements of ERAS for pre-, intra-, and post-operation procedures as introduced in the selected articles. The clinical outcomes were divided into patient-reported (PRO) and clinician-reported outcome (ClinRO). Then, we listed the acupuncture interventions that are expected to produce clinically significant outcomes based on the existing general findings on acupuncture. Next, we looked at the pre-, intra- and post-operation procedures independently and allocated the respective acupuncture therapy to each procedure.

\section{Outcome Assessment}

To assess the benefits of acupuncture, we assessed the differences between means in the acupuncture and control groups in the reviewed studies and summed up PRO and ClinRO. In the case of multiple measures, the difference of the conservative values was considered. Our rating was based on the benefit ranking system indicating a symptom improvement of $\geq 30 \%$ as clinically significant ('good' level), an improvement of $20-30 \%$ as 'fair' and $10-20 \%$ as 'not bad' [4].

\section{Results}

\section{Acupuncture-extended ERAS Programme}

To evaluate effectiveness of acupuncture in each phase of operation, we identified 16 main components of the gynaecological ERAS programme [5].

In the pre-operative phase, the medical staff informed the patient about the process and estimated outcome of the operation. Solid food fasting for $6 \mathrm{~h}$ and clear liquid fasting for $2 \mathrm{~h}$ prior to

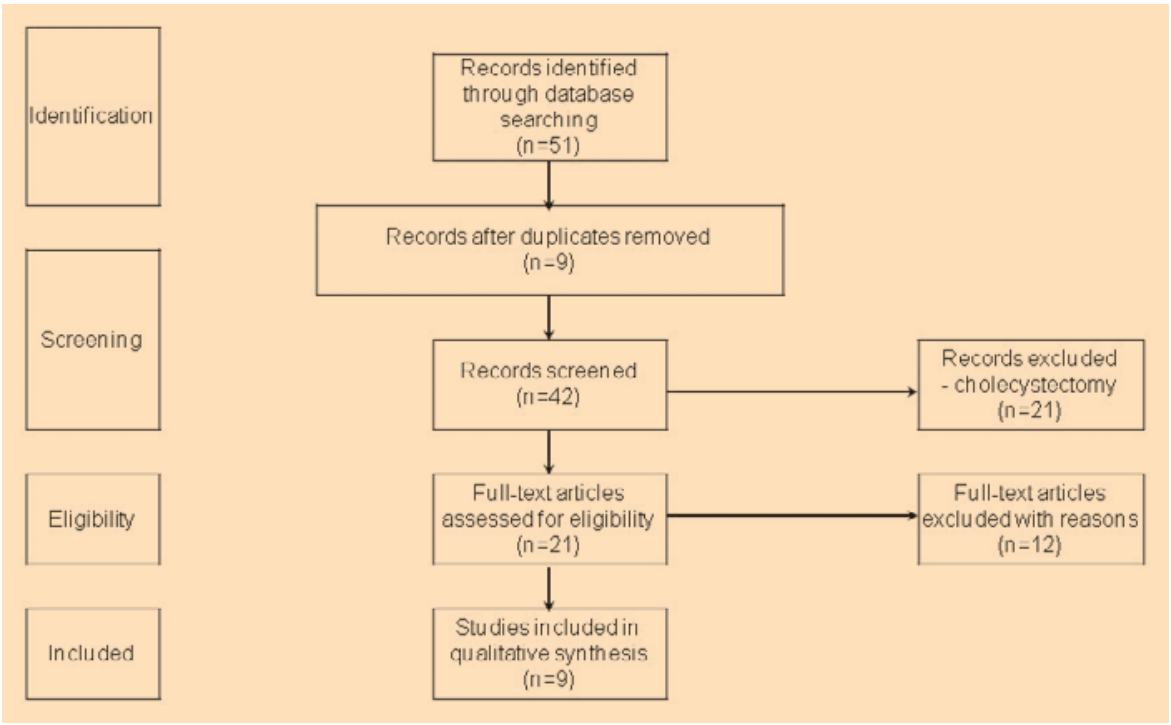

Fig. 1. Flowchart of the present study based on PRISMA. 
Table 1. Enhanced recovery after surgery (ERAS) programme with acupuncture

\begin{tabular}{|c|c|c|c|c|}
\hline \multirow[t]{2}{*}{ Operative phase } & \multirow[t]{2}{*}{ Elements of treatment } & \multicolumn{2}{|l|}{ Clinical outcomes } & \multirow[t]{2}{*}{ Applied modality } \\
\hline & & patient-reported & clinician-reported & \\
\hline \multirow[t]{3}{*}{ Pre } & information and counselling & anxiety-depression scale & & acupuncture \\
\hline & fasting and carbohydrate loading & & $\begin{array}{l}\text { first passing flatus } \\
\text { first bowel motion } \\
\text { resuming liquid diet } \\
\text { first defecation }\end{array}$ & \\
\hline & $\begin{array}{l}\text { pre-anaesthetic medication } \\
\text { antimicrobial prophylaxis }\end{array}$ & sleep quality index & tranquilliser consumption & acupuncture \\
\hline \multirow[t]{2}{*}{ Intra } & $\begin{array}{l}\text { standard anaesthetic protocol } \\
\text { preventing post-op nausea and } \\
\text { vomiting }\end{array}$ & symptom scale & $\begin{array}{l}\text { anaesthetic consumption } \\
\text { number of emetic episodes }\end{array}$ & $\begin{array}{l}\text { acupressure } \\
\text { acupressure }\end{array}$ \\
\hline & $\begin{array}{l}\text { surgical incision } \\
\text { prevention hypothermia } \\
\text { perioperative fluid management }\end{array}$ & & minimal incision & \\
\hline \multirow[t]{5}{*}{ Post } & urinary drainage & & $\begin{array}{l}\text { removing urinary catheter } \\
\text { urinary catheter re-insertion }\end{array}$ & $\begin{array}{l}\text { acupuncture } \\
\text { cupping }\end{array}$ \\
\hline & prevention of ileus & & $\begin{array}{l}\text { first passing flatus } \\
\text { first bowel motion } \\
\text { resuming liquid diet } \\
\text { first defecation }\end{array}$ & $\begin{array}{l}\text { acupuncture } \\
\text { cupping }\end{array}$ \\
\hline & $\begin{array}{l}\text { analgesia } \\
\text { nutrition care } \\
\text { early mobilisation }\end{array}$ & $\begin{array}{l}\text { pain intensity } \\
\text { symptom scale }\end{array}$ & $\begin{array}{l}\text { analgesic consumption } \\
\text { walking independently }\end{array}$ & acupuncture \\
\hline & nurse led follow-up & $\begin{array}{l}\text { quality of life } \\
\text { patient satisfaction }\end{array}$ & complications & $\begin{array}{l}\text { acupuncture } \\
\text { moxibustion } \\
\text { Hand acupuncture }\end{array}$ \\
\hline & audit & & & $\begin{array}{l}\text { moxibustion } \\
\text { hand acupuncture }\end{array}$ \\
\hline
\end{tabular}

surgery were assumed to influence the early recovery of GI motility. Pre-anaesthetic medication for sedation and antibiotic prophylaxis for infection prevention were also considered [6]. It was found that in this phase, acupuncture enhanced the alleviation of psychological stress by improving anxiety and depression as well as the sleep quality index, thereby potentially enhancing patient compliance towards operation $[7,8]$.

In the intra-operative phase, a minimally invasive incision on the operative site was made, along with local anaesthesia [9]. As anaesthesia causes PONV as typical adverse reaction, acupressure was applied as potential measure to alleviate the symptoms. Indeed, in this phase, acupressure reduced the symptom level so that the patients were more comfortable.

In the post-operative phase, pain control, recovery of GI, recovery of urinary function, early oral nutrition and early mobilisation were identified as the main aims of ERAS. In general, ERAS was effective in preventing major and minor post-operative complications and provided careful follow-up [10]. In this phase, multimodal complementary and alternative therapies, such as acupuncture, acupressure, cupping, moxibustion and hand acupuncture were actively used in the reviewed studies to accelerate recovery by reducing pain intensity and several symptom scale parameters, including time to remove urinary catheter, first passing flatus, bowel motion, liquid diet, defecation and walking independently. Thus, the application of acupuncture improved quality of life and patient satisfaction (table 1).

\section{Benefits of Acupuncture in ERAS Programme}

Firstly, we identified symptoms potentially alleviated by acupuncture, reaching from $8 \mathrm{~h}$ to 5 years. The identified therapeutic modalities were acupuncture, acupressure or hand acupressure.

Acupuncture was employed in PONV, pain and urinary retention using acupoints ST36, SP6, ST28 and CV8. The first 3 acupoints belong to the meridians of the gastrointestinal system; the latter acupoint involves the meridians of the reproductive system. Several auricular acupoints were identified, including shen men i.e. 'heavenly gate') effectively controlling pain and being useful in treatment of anxiety, sedation and inflammation. The CV8 acupoint, an abdominal acupoint, was also selected for adjunctive therapy with moxibustion [11-13]. 


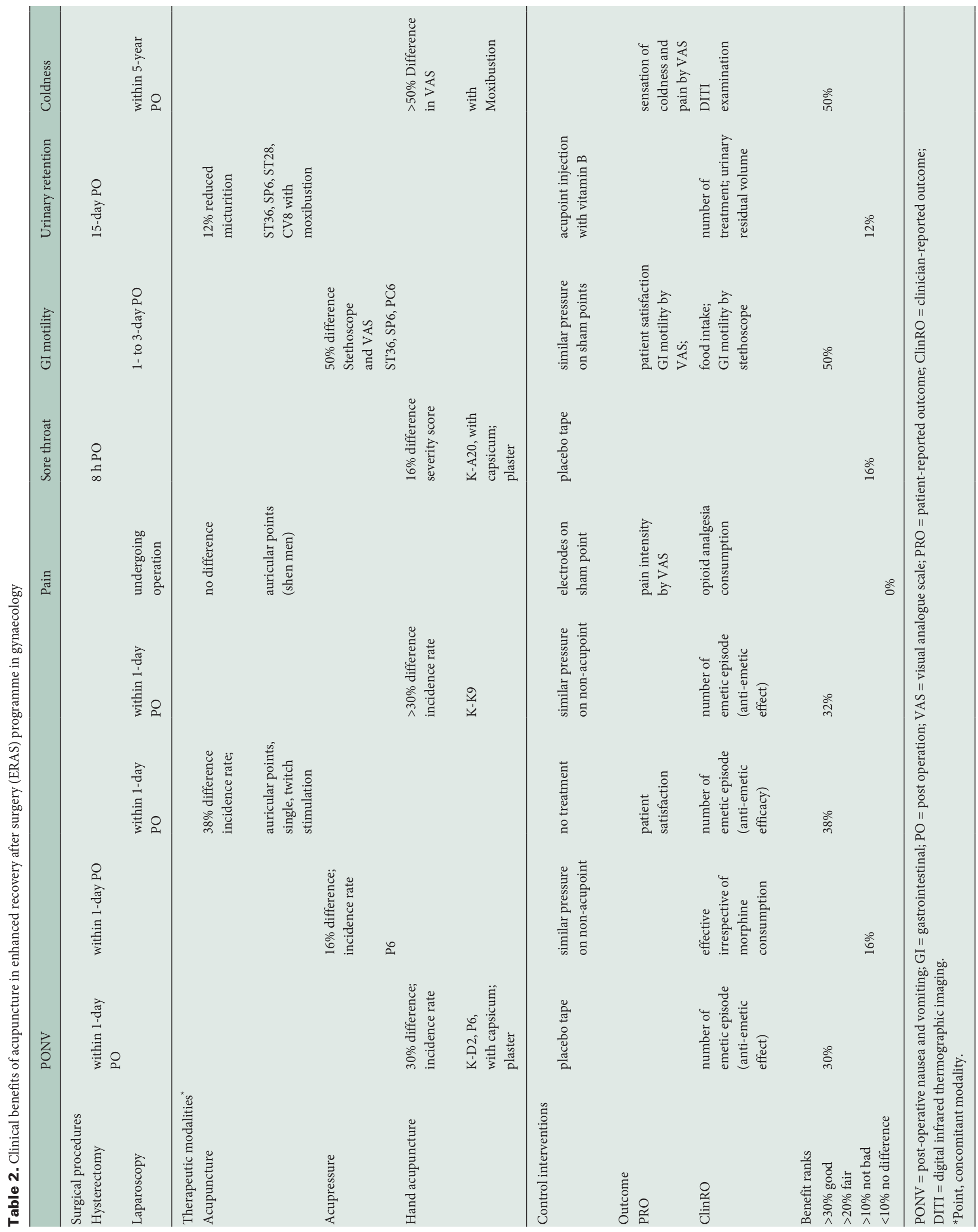


Acupressure was adopted to relieve PONV and to accelerate GI motility. Acupressure point selection was similar to acupoint selection, i.e. P6, ST36 and SP6 $[14,15]$.

Hand acupuncture was utilised for PONV, sore throat and coldness, the latter being tentatively defined as a chilled state due to uneven circulation of qi and blood according to yin and yang theory. The selected points were the newly defined points, K-D2, $\mathrm{K}-\mathrm{K} 9$ and K-A20 including the standardised point P6. Hand acupuncture was performed along with e.g. capsicum plaster or moxibustion [16-19]. Control interventions involved placebo tape, similar pressure on non-acupoint, no treatment, electrodes on sham point, or acupoint injection with vitamine B.We reviewed the results of 3 studies on acupuncture for PONV as 'good', indicating $30 \%$ symptom relief. The GI motility and studies on coldness also showed 'good' results. The improvements in sore throat, urinary retention and PONV in 1 study were ranked as 'not bad'. Interestingly, there was no difference in pain.

The PROs of the PONV studies showed a higher degree of patient satisfaction after acupuncture, and ClinRO assessment showed a reduced number of emetic episodes (anti-emetic effect). For symptoms of GI motility, the acupressure-treated patients showed improvement (PRO) based on self-reporting questionnaires including visual analogue scale (VAS). The ClinRO was assessed by stethoscope. The PRO for urinary retention suggested that acupressure shortened the course of treatment, and the ClinRO suggested that acupressure decreased the urinary residual volume.

Hand acupuncture treatment for coldness showed pain relief, as indicated by the patients, and increased the internal body temperature, as indicated by the clinicians using DITI examination (table 2).

\section{Discussion}

In this study, we introduced the ERAS programme involving acupuncture for pre-, intra-, and post-operative gynaecological surgery. As shown in this review, acupuncture alleviates surgical stress, reduces the emetic symptom and accelerates recovery from complications in pre-, intra-, and post-operative phases, respectively. For the implementation in practice, acupuncture was found to play a beneficial role by improving PRO, such as treatment satisfaction, VAS and sensation of coldness. These findings support the usefulness of acupuncture to alleviate symptoms of post-operative conditions, such as PONV, urinary retention and coldness as well as to enhance GI mobility after surgery.

To evaluate benefits of acupuncture in gynaecological surgery, we focussed on the ERAS programme as a standard clinical pathway to achieve early recovery for patients undergoing major surgery. We believe that acupuncture can improve the potential, range and effectiveness of this programme since its framework is not selfcontained, last but not least in order to achieve improvements in patient-centred medicine [20].

Enhancement of recovery can be measured in 2 domains: PRO and ClinRO. PRO reports the status of a patient's condition that is directly provided by the patient $(\mathrm{PRO})$ beyond a professional inter- pretation (ClinRO) [21]. An important outcome in both domains is the number of in-patient days as discharge criteria relate to reduced symptom levels, programme compliance, satisfaction of patients and other factors [22]. Both PRO and ClinRO are important for determining the discharge and nurse-led follow-up. PRO could serve as a key factor to update this ERAS programme facilitating patient-centred and personalised medicine.

There is evidence suggesting that acupuncture only alleviates post-operative symptoms [23]. Unfortunately, acupuncture in ERAS alone provides no additional significant measure except for its value as a CAM modality. However, superiority of integrative medical care had already been proven in various studies [24, 25]. In this study, no values were identified for pain, which could be assessed according to consumption of analgesic agents or a patientreported VAS scale during hospitalisation [28]. Opioid analgesics have a strong effect on acute pain control; thus, the effect of acupuncture is potentially masked during hospitalisation. However, acupuncture may be able to significantly alleviate the chronic pelvic pain that is often observed after hysterectomy [29].

In the pre-operative phase, acupuncture can relieve surgical stress and increase compliance for the success of the operation given that it ameliorates anxiety, emotional stress and depression [26]; it also can decrease adverse reactions to anaesthetic agents [27]. During the post-operative phase, acupuncture can successfully manage complications by increasing GI motility, preventing urinary retention, and alleviating PONV within 1 month after surgery. Moreover, acupuncture offers good supportive care in the treatment of post-operative fatigue, chronic pain, coldness and mood disorders, thereby resulting in improved health-related quality of life. Yet, it is difficult to measure the direct and sole effect of acupuncture as it is often masked by analgesic agents [28] having strong effects on acute pain control. However, acupuncture may be able to significantly alleviate chronic pelvic pain that is often observed e.g. after hysterectomy [29]. In South Korea it is quite common that adult hysterectomy patients who suffer from decreased physical and weakened emotional functions tend to visit traditional Korean medical clinics to receive acupuncture, moxibustion, herbal therapies or hand acupuncture for enhanced recovery. This local situation would provide the feasible model for ERAS with acupuncture giving a basis for implementation in practice. However, the introduced model needs to be tested in controlled clinical trials [30].

Due to difficulties in summarising the control interventions and the limited number of reviewed studies, no statistically clear conclusion of acupuncture efficacy can be drawn in this context. However, according to positive PRO and ClinRO for acupuncture in gynaecological surgery, this CAM method has beneficial potential to enhance ERAS and to help alleviating symptoms after surgery.

\section{Acknowledgements}

We especially thank Dr. Gunhyuk Park for his critical advice on manuscript formatting and Dr. Joon-Seag Ahn of the Yonsei Boramae East-West Integrative Medical Clinic for his advice on future directions of the study. This study was funded by the Korea Institute of Oriental Medicine (KIOM, Grant no.K15253). 


\section{Disclosure Statement}

The authors declare that there is no conflict of interests concerning this paper.

\section{References}

1 Wodlin NB, Nilsson L: The development of fast-track principles in gynecological surgery. Acta Obstet Gynecol Scand 2013;92:17-27.

2 Pilkington K, Kirkwood G, Rampes H, Cummings M, Richardson J: Acupuncture for anxiety and anxiety disorders - a systematic literature review. Acupunct Med 2007;25:1-10.

3 Cheong KB, Zhang JP, Huang Y, Zhang ZJ: The effectiveness of acupuncture in prevention and treatment of postoperative nausea and vomiting - a systematic review and meta-analysis. PLoS One 2013;8:e82474.

4 Williamson LN, Dhariwal KR: Bioequivalence testing in the U.S. for generic drug products. www.fda.gov/ downloads/Drugs/NewsEvents/UCM182556.pdf (accessed 10.03.2015).

5 Carter J: Fast-track surgery in gynecology and gynecologic oncology: a review of a rolling clinical audit. ISRN Surg 2012;2012:368014.

6 Wodlin NB, Nilsson L, Arestedt K, Kjolhede P, Group GS: Mode of anesthesia and postoperative symptoms following abdominal hysterectomy in a fast-track setting. Acta Obstet Gynecol Scand 2011;90:369-379.

7 Kjolhede P, Langstrom P, Nilsson P, Wodlin NB, Nilsson L: The impact of quality of sleep on recovery from fast-track abdominal hysterectomy. J Clin Sleep Med 2012;8:395-402.

8 Kjolhede P, Borendal Wodlin N, Nilsson L, Fredrikson $\mathrm{M}$, Wijma K: Impact of stress coping capacity on recovery from abdominal hysterectomy in a fast-track program: a prospective longitudinal study. BJOG 2012; 119:998-1006

$\checkmark$ Borendal Wodlin N, Nilsson L, Kjølhede P, GASPI study group: The impact of mode of anesthesia on postoperative recovery from fast-track abdominal hysterectomy: a randomised clinical trial. BJOG 2011;118: 299-308.

10 Kehlet H, Wilmore DW: Evidence-based surgical care and the evolution of fast-track surgery. Ann Surg 2008; 248:189-198.
11 Holzer A, Leitgeb U, Spacek A, Wenzl R, Herkner H, Kettner S: Auricular acupuncture for postoperative pain after gynecological surgery: a randomized controlled trail. Minerva Anestesiol 2011;77:298-304.

12 Kim Y, Kim CW, Kim KS: Clinical observations on postoperative vomiting treated by auricular acupuncture. Am J Chin Med 2003;31:475-480.

13 Yi WM, Pan AZ, Li JJ, Luo DF, Huang QH: Clinical observation on the acupuncture treatment in patients with urinary retention after radical hysterectomy. Chin J Integr Med 2011;17:860-863.

14 Alkaissi A, Evertsson K, Johnsson VA, Ofenbartl L, Kalman S: P6 acupressure may relieve nausea and vomiting after gynecological surgery: an effectiveness study in 410 women. Can J Anaesth 2002;49:1034-1039.

15 Chen LL, Hsu SF, Wang MH, Chen CL, Lin YD, Lai JS: Use of acupressure to improve gastrointestinal motility in women after trans-abdominal hysterectomy. Am J Chin Med 2003;31:781-790.

16 Boehler M, Mitterschiffthaler G, Schlager A: Korean hand acupressure reduces postoperative nausea and vomiting after gynecological laparoscopic surgery. Anesth Analg 2002;94:872-875.

17 Kim KS, Koo MS, Jeon JW, Park HS, Seung IS: Capsicum plaster at the Korean hand acupuncture point reduces postoperative nausea and vomiting after abdominal hysterectomy. Anesth Analg 2002;95:1103-1107.

18 Park HS, Kim KS, Min HK, Kim DW: Prevention of postoperative sore throat using capsicum plaster applied at the Korean hand acupuncture point. Anesthesia 2004;59:647-651.

19 Shin KR, Kwak SA, Lee JB, Yi HR: The effectiveness of hand acupuncture and moxibustion in decreasing pain and 'coldness' in Korean women who have had hysterectomy: a pilot study. Appl Nurs Res 2006;19:22-30.

20 Wodlin NB, Nilsson L, Kjolhede P: Health-related quality of life and postoperative recovery in fast-track hysterectomy. Acta Obstet Gynecol Scand 2011;90: $362-368$.
21 Deshpande PR, Rajan S, Sudeepthi BL, Abdul Nazir CP: Patient-reported outcomes: a new era in clinical research. Perspect Clin Res 2011;2:137-144.

22 Wijk L, Franzen K, Ljungqvist O, Nilsson K: Implementing a structured Enhanced Recovery After Surgery (ERAS) protocol reduces length of stay after abdominal hysterectomy. Acta Obstet Gynecol Scand 2014;93:749-756.

23 Yi WM, Chen Q, Liu CH, Hou JY, Chen LD, Wu WK Acupuncture for preventing complications after radical hysterectomy: a randomized controlled clinical trial. Evid Based Complement Alternat Med 2014; 2014:802134.

24 Otti A, Noll-Hussong M: Acupuncture-induced pain relief and the human brain's default mode network an extended view of central effects of acupuncture analgesia. Forsch Komplementmed 2012;19:197-201.

25 Lee SH, Lee IS, Cho HS, Kim KK: Effect on orientalwestern medicine integrative care after gynecological surgery. Korean J Obstet Gynecol 2011;24:127-145.

26 Gao X, Xu C, Wang P: Curative effect of acupuncture and moxibustion on insomnia: a randomized clinical trial. J Tradit Chin Med 2013;33:428-432.

27 Holmer Pettersson P, Wengstrom Y: Acupuncture prior to surgery to minimise postoperative nausea and vomiting: a systematic review. J Clin Nurs 2012;21: 1799-1805.

28 Musial F, Michalsen A, Dobos G: Functional chronic pain syndromes and naturopathic treatments: neurobiological foundations. Forsch Komplementmed 2008; 15:97-103.

29 Vickers AJ, Linde K: Acupuncture for chronic pain. JAMA 2014;311:955-956.

30 Roberti di Sarsina P, Alivia M, Guadagni P: Traditional, complementary and alternative medical systems and their contribution to personalisation, prediction and prevention in medicine-person-centered medicine. EPMA J 2012;3:15. 